\title{
Model of Marketing Innovative Strategies in International Entrepreneurship: A Global Business Environment
}

\author{
Bahram Sattari ${ }^{1} \&$ Javad Mehrabi ${ }^{2}$ \\ ${ }^{1} \mathrm{PhD}$. Candidate in International Entrepreneurship and Member of Young Researchers and Elite Club, Tabriz \\ Branch, Islamic Azad University, Tabriz, Iran \\ ${ }^{2}$ Department of Management, Qazvin Branch, Islamic Azad University, Qazvin, Iran \\ Correspondence: Bahram Sattari, PhD. Candidate in International Entrepreneurship and Member of Young \\ Researchers and Elite Club, Tabriz Branch, Islamic Azad University, Tabriz, Iran. E-mail: \\ Bahram.sattari@ut.ac.ir
}

Received: August 3, 2016

doi:10.5539/ass.v12n10p76
Accepted: August 16, $2016 \quad$ Online Published: September 19, 2016

URL: http://dx.doi.org/10.5539/ass.v12n10p76

\begin{abstract}
Today small and medium sized businesses are considered the principal factor for the growth of the industrial structure of many countries. To developing countries that are attempting to revive their economic structure, these industries are of great importance. Today, with the growth and advancement of technologies, the impact of cutting edge technologies such as information technology on the business environment cannot be overlooked. The use of innovative marketing helps create value. The purpose of this paper is to investigate innovative marketing and competitive advantages of small and middle sized businesses, with regard to the innovative approaches and the company's unique features. The statistical group of this study included 300 subjects working in the companies that are active in manufacturing disposable containers in Tehran province. The results of the study indicated that innovative marketing has impacts on the companies' competitive advantage. The unique features of the companies have no impacts on obtaining competitive advantage, but it affects innovative marketing.
\end{abstract}

Keywords: innovative marketing, competitive advantage, company features, entrepreneur approaches

\section{Introduction}

Small and middle sized businesses are the beating heart of today's economy of the world. With the beginning of the wave of industrialization and development of countries, a competition for creating major industries and mass and identical production was born and reached its peak in the first three quarters of the twentieth century. Although major industries are still demanding the attention of decision makers in economy because of their advantages that are results of their large scale, production domain, experience and organization effect, but the advantages of small and middle sized businesses, because of the transportation impact, market size and effectiveness of choice and control have turned these businesses into the first choice in most products (Jelodar et al., 2012).

In the current dynamic competitive environment, the success of each organization in keeping and increasing their share of the market and improving the competitive state depends on the identification of factors that cause the creation of competitive advantages. Obtaining competitive advantages in today's world has turned into one of the main challenges in different industries. Companies cannot be regarded among the best without competitive advantage. In other words, companies which have been successful and are considered to be among the best are those that have competitive advantage. Competitive advantages include a set of factors or capabilities that always enable the company to show a better performance from the other competitors (Sadri \& Less, 2001).

The innovation process is filled with disagreements and contradictions. Balancing these contradictions is a challenge that any one uses in order to find a way to use these tools of innovation to realize the needs of different parties. These contradicting expectations need the creation of a balanced process in order to realize the needs through innovation management (Gumus et al., 2015). Innovation leads to a change in the processes of organizations and is the main tool for using marketing strategies in accordance with the customers' and the market's interests, which in its turn, results in sustainable competitive advantage development. According to 
Peter F. Drucker, there is only one liable definition for business: creating customers. And entrepreneurship can only be defined based on two general factors: marketing and innovation. Innovation is the use of organizational properties and qualifications. Innovation processes lead to the presentation of new products to the market and creation of value for the company (Canagel, 2015). Obtaining competitive advantage is often a function of pioneering in innovative activities. The above mentioned competitive advantage is caused by the access to properties that support business activities and is the prize for pioneers. The followers of the market normally face several problems and higher profits are only obtained through innovation. Innovation is a key element in entrepreneur activities. Businesses that have higher levels of innovativeness have shown better performances. For instance, the success of the Japanese automobile manufacturing business lies mostly in the innovation process (Sattari et al., 2013).

Nowadays, no country is living separately from other countries completely. The economic resources, technology and living standards of a country depend on other countries' economy, which in turn are related together by the complex flow of goods, services, capital and technology (Gura, 2007). Through international exchanges, countries raise their production levels and earn more profits. Through importing, they purchase the goods that they are not able to produce, and ship the surplus goods to other countries (Pierce et al., 1998). With an increase in international trade among different countries and the emergence of new global actors, several competitive advantages are gaining momentum. The reduced trade barriers in emerging markets of the developing countries create new opportunities and comparative advantages. World economic globalization has increased the competitive advantage in global markets. Compared to developed countries, which are of the upper level industry, this is important for the countries in emerging markets that have great work forces (Hau, 2014). The exports positively affect the level of employment, foreign exchange earnings, industrial development and national prosperity. While improving corporate performance, this has increased the profitability, sales volume and market share. Under the globalization and economic integration among countries, the export and international strategies of the companies become more and more important (Mehmet et al., 2010).

Due to the increased global trade and intensified competition around the world, many companies have started to seek for growth opportunities, risk of business diversification to increase their profits. However, the key drivers of companies' export performance to distinguish have received the attention of many academics, administrators and decision makers around the world. They focused on the role of marketing capabilities and competitive advantage for the companies to explain the export performance. There are marketing capabilities as a complex package of skills, knowledge and applied organizational processes that enable the companies to coordinate the activities and use the assets. The international companies have continued globalization by increasing competitive rates in international markets, and the possession of capabilities that can be tailored to the needs of foreign customers is important for the developing companies. Hence, the identification and understanding of marketing capabilities act as a lever to gain competitive advantage. Various studies suggest shortcomings in identifying factors affecting the competitiveness advantage in the global context (Carroll \& Sosa, 2015).

Being successful in the international market is related to the efficient and effective implementation of the marketing mix planned strategy for a specific market (Souza et al., 2008). Therefore, the revised internal strategy is required when entering into a new market, due to different characteristics of the international market. The companies are forced to design and implement a suitable marketing method, if they are interested in entering into a new market. They have to weigh the cost and complexity of saving strategies based on international standards and market consistent strategy, derived by the marketing mix (Beigi \& Naserkhani, 2013).

The marketing is considered as a base for the creation of value for shareholders and customers. Therefore, marketing task is to consider the needs of customers and to build trust and loyalty among their customers and provide the expected value for the organization. Marketing, like the other rules of trade, should be adapted to changing technologies (Doyle, 2008).

The importance of goods and diversity of export can be essential for the economic growth and development (Aditya \& Acharyya, 2013). The emerging literature concern is related to new export levels of countries. The most important decisions have been taken at the corporate level for the introduction of new products for export. The diversity of products offers is to reduce uncertainty at the international level and increase the competitive advantage. In reviewing the factors affecting the export performance, these studies have focused on the exchanges and increased productivity based on the innovate efforts (Sierra et al., 2015).

The innovation leads to the trend of changing the organizations and to the suggestion of the new markets as essential keys used in marketing strategy based on the interests of customers and markets leading to development in sustainable competitive advantage. According to Peter Drucker (1954), there is only one valid definition of 
business purpose: creating a customer and a business is only based on two functions: "Marketing and innovation" (Kanagl, 2015).

While many studies have been conducted to discuss entrepreneurial and innovative marketing issues, this is a tool for growth and investment efficiency that help us understand the importance of the interaction between entrepreneurship and marketing innovation (O' Dwyer et al., 2009). New developments have taken place in entrepreneurial and innovative marketing that examine the interaction between these factors, individually, but there is no comprehensive theory on this subject (Krauss, 2010).

At the present, the main motto is "creativity and innovation", and nowadays companies have recognized that innovation is necessary, and the thinking and ideas of innovations have influenced the inside of the administrative structures. As with the growth, the dynamics and even the survival of modern organizations depend on applying the innovation. If the organizations and their managers want to survive and prosper in the long term, they must be innovative and continually adapt to the new situation. What has always occupied the minds of entrepreneurship researchers is why some small businesses with marketing innovation can become medium and large companies, but others cannot (Sattari et al., 2013).

The material presented can be derived as the fact that as there are research gaps in academic studies in the field of marketing innovation, the marketing innovation should be investigated within the turbulent business environment of Iranian companies and organizations. Given that the basis of competition and competitive advantage acquired in the business world today is to enjoy the innovation strategy based on strategic entrepreneurship. In this research, the innovative marketing on the international entrepreneurship is surveyed. The innovative marketing and innovative international entrepreneurship concepts are discussed. Using structural equation modeling, the research model is discussed.

\section{Literature Review}

\subsection{International Trade, Globalization and Entrepreneurship}

The confusion has been increasing about globalization. Theoretically, the internationalization includes different levels such as: world, nation, state, society, organization and individual. Knight (2004) showed that the increase in international attention to internationally communicate. However, much of the confusion is associated with the concept. In the past two decades, the definition of the term has been evolved. "Internationality" was first defined at the organizational level and in terms of collection of activities. However, many definitions have evolved and researchers have considered them from various angles, including strategic management, organizational learning and strategic change leader (Horn et al., 2007; Stromquist, 2007). A term applied by people with different goals for internationalization is the transformation from a general to another general case internationally, in any aspect and in all dimensions (Li-Hua, 2011).

The term "internationalization" includes moving from the inside to the outside in order to engage in international business. Callovi and Bmynsh (1995, p. 116) defined the internationalization as "Companies' operation adaption process such as strategy, structure, resources etc., with international environments". One of the traditional methods that prevail in internationalization is the "Uppsala model". According to this model, the company begins to operate in the domestic markets and do not have any exports. Having established a strong domestic market, an agency begins to export. Then a collection of affiliated companies is established to buy from and sell to the foreign markets and finally, a manufacturing company is formed within the foreign market. Also, the process refers to international mode that direct exports and the agencies are considered and this starts the low-level commitments and sales mode and the commitments increase after establishing manufacturing companies. The first foreign export market of a company will have a psychological distance close to the domestic market. The psychological distance includes the same language, culture, economic development and business practices, which are similar to the domestic market. Johansson and Vale (1975) emphasized the value of experiential knowledge and suggestions that are produced within the international process and are implemented gradually leading to an increase in the market knowledge of company and creation of the market activity (Chat \& Stangl, 2010).

However, according to the researchers of the globalization, due to rapid technological changes and liberalization of growing economies, the internationalization process is exited from a gradual mode and has taken rapid pace (Chat \& Stangl, 2010).

One of the common perceptions of internationalization means the internationalization and globalization of the values. From this perspective, the word "international" has cross-border relations. In this sense, Paul Hirst and Graham Thompson had defined the internationalization to be the massive flow of growing trade and unleashing 
capital between countries. Evidence of this kind of the internationalization can be seen as the dramatic acceleration of communications and media, and transmission of messages and ideas among countries that are more centered on the global economy. For example, cross-border global presence and developing internationalization process means the concept of becoming the homogeneous capital at the global scale, which is an outstanding kind of growing acceleration (Jolan \& Jamal, 2008).

The relationship between the trade and the entrepreneurship is explained in several approaches: according to the exports, there is the foreign demand for export goods; if any, an increase in the capacity of productions exported is resulted in. This requires the capacity or applying the skills or the workforce with higher productivity and other sufficient resources. On the other side, the increased export creates the competitiveness fields in the manufacturing firms that these factors lead in the production cycle to innovation, acquired higher skills and the emergence of new firms, and the new activities of firms (Taiebi \& Fakhry, 2010).

As part of the new research in the field of international entrepreneurship, there are some definitions for internationalization. McDougall and Oviatt (2000) found that the internationalization should be the combination of innovation, risk-taking and active behavior that pass the national borders and create value for the organization. Under these aspects, it has been proposed to recognize and use the opportunities. McDougall and Oviatt (2005) had stated the term "international entrepreneurship" as the discovery, applying, evaluating and exploiting opportunities, which is an essential part of the international strategies of a company (Kopp \& Gassmann, 2009).

In this study, the international focus is on the organizational level. Internationalizations defined as the international integration processes and intercultural dimension for teaching, research and service performance of the institution". This approach towards the international, in academic's viewpoint, can be considered as a multi-dimensional and inter-disciplinary concept (Hao et al., 2011).

The entrepreneurship is the process started by identifying the service by a person who has usually visionary thinking and risk-taking, and then after going through various stages, including the idea finding, screening of ideas, feasibility and business plan development etc., it leads to the formation of the company and developing the properties of this process, and the existing framework destruction by creative demolishing with replacement of the new framework. The international entrepreneurship is a combination of innovative, active and risk-taking behaviors that by crossing the border are seeking value in the organizations. Wright and Ricks, two international business researchers, in 1994introduced the international entrepreneurship as a new area including two issues: comparison of entrepreneurial behavior in different countries and cultures and organizational behaviors developed among the different countries through crossing the borders (Oviatt \& McDougall, 2007).

It seems that there is a positive relationship between active search for new opportunities or innovative responses to the changing environment of a firm export performance (Ritz et al., 2007).

\subsection{Innovative Marketing}

In the new millennium, the theoretical framework of international trade was created due to improvements in the economy under changing technology. In fact, the main problem in the field of business models in different countries can be the behavior of technology and innovation. Some initial studies such as STO (1987), Porter (1990) or DB et al. (1990) provided an overview of the relationship between innovation and internationalization through the analysis of macro-economic factors. In general, the studies on the internal ability of companies and innovative performance mainly have been considered for economic assessment, according to assessment approaches, and innovation behavior (Rodil et al., 2015).

The management research has cited the importance of innovation and there are different definitions of this concept in the literature. Thompson (1956) has defined the innovation: "The creation, acceptance and using of new ideas, processes, products or new services." Linder et al. (2003) has defined the innovative as the use of new idea creating the value. In more recent research, the innovation is called by creation of and using the products, services and new goods or improving existing methods, which aims to increase the company's competitive advantage (Foreman, 2011). The innovation activities are a complex process that occurs in several stages (Hollenstein, 2003).

In today's dynamic and changing environment whose source is an increase in the competition of globalization and the emergence of new technologies, the innovation is a way of development and achievement of high performance and survival in the global economy. Being a leader compared with the competitors requires desire and ability of the organization to create and to commercialize the processes, products and new business systems or this is the same innovation that helps the companies to be different. The innovation can be seen as part of the organizational culture and can be defined as the tendency of organization to the innovation (Shakeri et al., 2011). 
Different types of innovation have been discussed by various authors. The studies are in three fields of innovation in the outputs, inputs and processes. For example, Schumpeter (1934) considered the innovation domains to be the new product or service, development of new methods of production, identification of markets, exploring new sources of supply and the development of new organizational forms. Miller and Friesen (1983) referred four dimensions of the product or service, methods of production or services, risk-taking in executive plan and exploring new and unusual solutions. Capon et al. (1992) defined three dimensions of organizational innovation as the innovation in the market, strategies, and technological skills. But, in general, three forms of innovation in products, processes or new business systems are considered by more authors (Crespell \& Hansen, 2007; Hovgaard \& Hansen, 2004; Knowles et al., 2007). Thus, the innovation is defined as willingness and ability of the organization to adapt and develop the innovative forms in product shape, service, process or business system (Crespell \& Hansen, 2007).

Innovation can be considered in different types including innovation in product, process technology, marketing and non-technological affairs organization (Evangelista \& Vezzani, 2010). This is not possible to combine the two concepts of innovation and marketing together in the field of innovation, and this is considered as the bottleneck for many researchers (Weizhen, 2009). Peter Drucker was the first person who combined the two concepts together (Weizhen, 2009; Oudrhiri et al., 2009). The relationship between marketing and innovation can be called a bilateral interaction and effectiveness and making connections between the innovation and the marketing, it can be reached a sustainable competitive advantage (Oudrhiri et al., 2009). Several studies would be exploring the marketing strategies and different marketing elements were known. In product strategy, the companies often choose standard levels and such a strategy leads to the maintenance of the competitive advantage of the companies, which is responsible for creating the scale saving and savings in operating costs and strengthening the business position in export markets (Vrontis et al., 2009). Also, the companies with the further ability and resources often employ those people using the competitive price under the market selling conditions and choosing the compatible strategies with the price (Myers et al., 2002). There are problems in determining the appropriate strategy. The factors affecting this include networks, channels, logistics, and transportation. Some authors have shown that large companies may succeed by adopting standards because they can establish a close relationship in the distribution, leading to a reduction in uncertainty between benefit conflictions, and creating the dominant procedures distribution (Robles, 2011). In a promotional strategy, for large enterprises, the needs of customers in light of contradictory communication of effective messages should be taken into account, which gives rise to the cost savings of quality control more (Okazaki et al., 2006). Companies' export experience has been effective in the selection and implementation of marketing strategies. The experienced companies are significantly trying, when selecting the product pricing strategy commonly, to consider gaining a competitive advantage with respect to the accumulated knowledge of customers for different markets (Chang, 2007). Also, in pricing strategies, by considering the exporters 'international experience and having more knowledge than their customers, they can use various strategies for pricing with regard to the customers' purchasing power within the different markets. The marketing strategy of the companies depending on their capital ownership is different from the multinational companies and those operating in developing countries. In developing countries, compared to domestic companies, the companies are obliged to use the strategies that have been set for them by the mother company and should act in accordance with those standards to meet consumers' needs. These companies often use the pricing strategies consistent with their consumers' needs that they can be able to be the winners of the market and this is able to maintain existing market share. The authors also point out that some multinational companies and foreign companies operating in developing countries have appropriate infrastructure, more funds for investment in research and development, human resources, engineering-technology, management and marketing expertise, so a greater chance of success in implementing its export strategy in competitive markets (Sodarvik et al., 2015).

The literature of marketing behavior in small and medium sized companies and that of innovation has been formed and used on the basis of competitive advantage. Marketing role in innovation is to provide concepts, tools, and infrastructures to eliminate the gap between current and ideal position, to achieve competitive advantage. However, this advantage is based on the innovation and marketing, but more a combination of innovative developments from non-nuclear activities in the marketing. Cummins et al. (2000) found that the innovative marketing includes all marketing activities and its profitability objectives are clear. In addition, the innovative marketing would be a reactive marketing is a result of the changes, which are continuously, or complementary enhancements that are based on the existing activities. The innovative behavior means the owner or manager exploit the opportunities. The innovative marketing is considered as "doing something new with new ideas, new products or new technology and refining these ideas in response to the market demand, according to a new method." Kindle et al. (1996) showed the innovation may include the new product development or the 
innovative developments in various aspects of marketing (Cummins et al., 2000). This innovation is a part of the constantly environmental assessment of a dynamic market that to ensure business growth in the competitive environment and the fight against the threats driven by the substitute products and services, it is necessary to increase the potential of newcomers and the bargaining power of suppliers. The innovative marketing is constituted by the basic elements classified into the classes of modification, focusing on the customer, integrated marketing, focusing on specific niche market and positions.

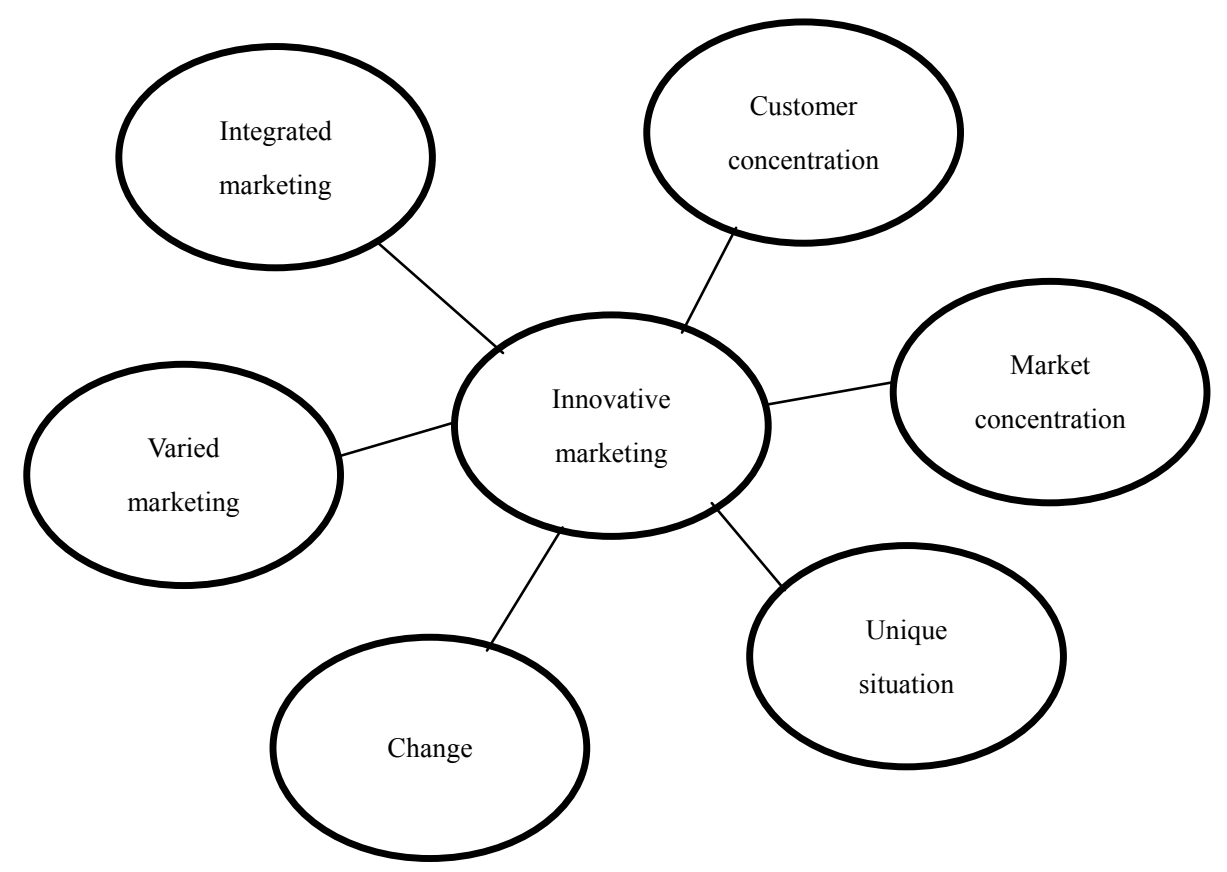

Figure 1. Innovative marketing strategies (Lancaster, 2007)

These elements illustrate the importance of innovation in marketing. When fully integrated in the organization's innovative marketing, to create the ability to respond to dynamic environment and be successful, they can force companies to achieve the organizational goals. Innovative marketing components are presented in Table 1.

Table 1. Innovative marketing variables (Lancaster, 2007)

\begin{tabular}{|c|c|}
\hline Innovative marketing variables & Elements \\
\hline \multirow{3}{*}{ Varied marketing } & Increased products \\
\hline & Changing the marketing \\
\hline & Changing distribution channel \\
\hline \multirow{2}{*}{ Change } & Active \\
\hline & Varied \\
\hline Focus on the customer & Focus on the customer \\
\hline \multirow{2}{*}{ Integrated marketing } & Integrated marketing \\
\hline & Marketing influence \\
\hline \multirow{3}{*}{ Focus on the market } & Vision \\
\hline & Market-based \\
\hline & Profit \\
\hline \multirow{3}{*}{ Unique situation } & New \\
\hline & Unique \\
\hline & Uncommon \\
\hline
\end{tabular}


The marketing strategies are related to the innovative marketing. The strategy is a combination of the creativity and quantitative and qualitative analysis. This combination helps to the companies in identifying new opportunities associated with the customers and market and shares the information about competitors. The marketing is a series of activities that are changing because the social science is changing.

Carson (1998) knew the main constituents of innovative marketing to be the product promotions and different distributions. Stokes (1995) considered the innovative marketing to identify new markets, correct the marketing mix and new operational systems. O'Dwyer et al. (2009) considered the innovative marketing consisting of six sections including marketing variables, modification and change, customer-oriented, integrated marketing, marketing-oriented, and unique place. The innovative marketing aspects are regarded as the foundation of the present study.

O'Dwyer et al. (2011), in addition to the six components of the previous research added the new component of a "strategic alliance" to the innovative components and stated that this component is the same networking in small and great companies, unofficially.

In today's competitive market, the competitive pressure has increased and the bargaining power of customers has increased, too. The customers are able to encounter with a huge flood of information and different quality products. In this stage, it is difficult to attract the customers and keep them in the market, based on the goals determined. In such a situation, the companies need to have an integrated strategy to consider a combination of insight of the market and company, brand positioning, processes, management and operational marketing, as shown in Figure 2 (Kiran et al., 2012).

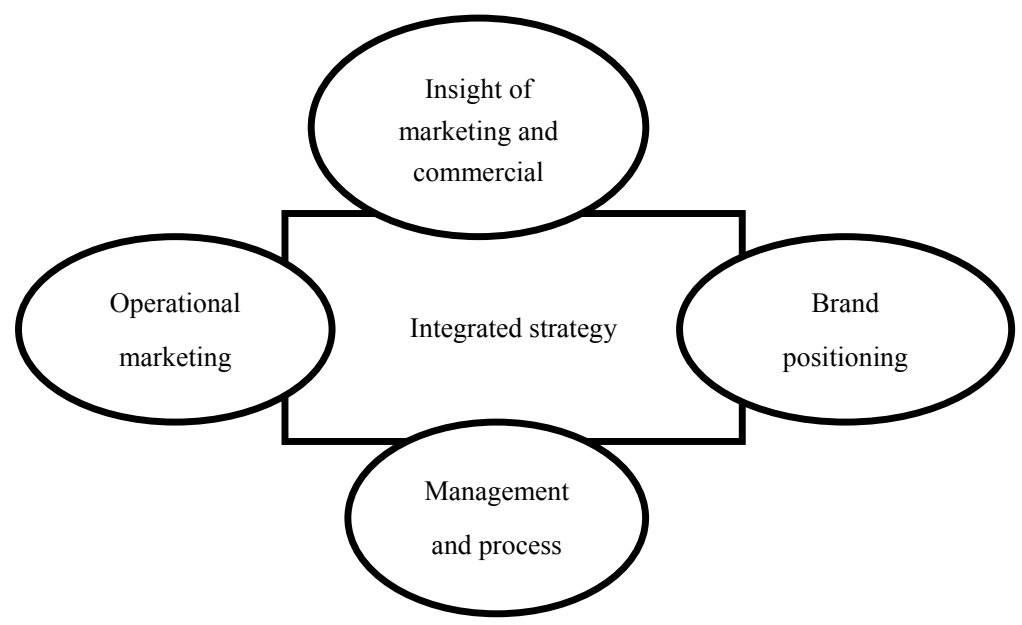

Figure 2. Integrated strategy of innovative marketing (Kiran et al., 2012)

Marketing and Commercial Insight: need to know the rules of the game. In this case it is important that small and medium-sized enterprises have a proper understanding of the pricing, location, situation of competitors and market behavior for their survival and innovation.

Brand positioning: It is very important for an organization to have a good understanding of the brand in customers' minds. This activity is made possible through the implementation of just $4 p$ strategy.

Operational Marketing: One of the major concerns in organizations is management of the supply chain. Therefore, to achieve a different position in the market, a company is a strong one with a very strong operational aspect, depending on these solutions of executive agent.

Processes and management: there is a lack of skills, technology and management in most organizations. Strong education, proper understanding of business, knowledge of the processes and the control of communications should beef the components of a successful strategy to sustain the Company.

The innovative marketing methods should be integrated and combined with the business strategy. In this way, the companies are able to compete and maintain their position in the global markets. Technological progress is not mentioned in the implementation of this integrated approach. For a proper execution of the innovative marketing strategies, the companies should implement technological developments for innovative marketing strategies:

Customer relation management: A business cannot survive without understanding the importance of CRM. The 
CRM can be accounted for as an important factor at this time. This is the easiest way to create a prominent role in international spaces and acquire the competitive advantage (Massharm \& Chavan, 2011).

The information and communication technology (ICT): the potential of information and communication technology leads to provide more benefits and wide productivity. The large companies invest heavily in advanced information technology that often, small companies suffer the gaps, from this point of view (Giannakouris and Smiley, 2010). The widespread use of information and communication technology can be vital to provide the innovative ideas and innovative marketing. IT can reduce costs at small businesses and improve the internal processes, improve product, communicate with customers rapidly and better promote and distribute the products through online presence. ICT plays an important role in the small and medium enterprise in domestic activity and external value chain, competitive performance and proper utilization of information and appropriate decision-making (Kiran et al., 2012).

The small and medium-sized companies do not need to focus exclusively on a small team or just marketing staff to generate new ideas; there is unlimited scope of application of the ideas in the company. Crediting brand in small and medium businesses should be considered responsibly and as the individuals' performance. The managers to employ the innovation in their activities have to use different methods to encourage and generate innovative ideas (Kiran et al., 2012).

Activities based on social responsibility (CSR): Today's consumers are well aware of social responsibility and this will affect their own understanding of the organization. Mainly in large companies, this issue will be considered further. But, these activities can be taken into consideration as a strategy tool for enhancing the competitiveness of small and medium-sized businesses. In general, CSR may affect SMEs' activities, and ultimately lead to improve the turnover and sales in the following ways (Kiran et al., 2012):

Creating better working conditions: it includes health and safety in the workplace, and it leads to higher motivation and loyalty among employees and thus enhances creativity and innovation.

- Improve environment friendly products and utilize the manufacturing processes that will lead to customer satisfaction and loyalty.

- CSR activities can take action to attract resources for charity, by using advertising campaigns.

- Businesses that rely on their own local customers focus to collect the donations can expand their communication through marketing verbally and or viral marketing.

\subsection{Cluster Approach}

Porter (2001) defined the clusters to be regional focus and the corporate network, specialized suppliers, service providers and associated institutions (e.g. universities, standards bodies and trade associations). The competition somewhat provides the areas of pre-competitive within the markets. Cluster members include complementary businesses rather than competitive businesses. Formal way in these clusters is to increase the marketing capabilities that in this case, the bargaining power increases and certainly it leads to get more government support and subsidies which ultimately to the achievement of potential customers (Kiran et al., 2012).

Literature review Maxwell (2011) explores the innovative marketing in the real estate investment firm. In this research, the innovative marketing challenges were investigated and entrepreneurial skills and marketing were explained that are needed to implement the innovative marketing. The results showed that the use of creative and innovative strategies for property sales has more influence over the sales activities and provided a good understanding of the customer.

Martinez et al. (2011) examined the innovative entrepreneurship and marketing. The study examined the concept of entrepreneurship and innovation. Finally, the innovative marketing model was offered that includes aspects of investments, identification of opportunities, and creation of entrepreneurship marketing, in order to facilitate organizational growth.

Kiran et al. (2012) explored the innovative marketing strategies for small businesses. In this study, a survey of small businesses in India showed that the assessment of organizational strategies and properly using the marketing capabilities and making innovative ideas of marketing would create the innovative strategies in the organization that improve the capability of small and medium businesses.

Marius et al. (2013) explored the marketing information systems as management tools of the operators in Africa. In this study, the innovative marketing was dealt with the tourism industry. The results showed that the managers' knowledge level of the new tools used in the marketing system play the role, which is decisive. The post-test results showed that the managers refuse to use the innovative marketing information in their decision making 
process.

Kanagal (2015) reviewed the innovation and product innovation in marketing strategies. In this research, the innovation and organizational change and changes in the marketing strategies were discussed, in line with the interests of customers and the market in order to gain competitive advantage. The results showed the innovation in marketing strategies would create shared value for the organization and the customer, and using innovative marketing methods should be in line with organizational strategies.

Sirsa et al. (2015) investigated how to distribute the export diversities through making innovation in Brazil's companies. The results showed that in the study of innovation in emerging economies, the access to resources cannot be conducive to export diversification. The innovative efforts and the company's strategic position in the domestic market are the significant factors in the creation of this export diversity.

Vicente et al. (2015) measured the capabilities of innovation in companies engaged in export. The results showed that the capabilities of innovation and creativity in organizations is higher than other aspects of product development capability, strategic one and technological ones that these four dimensions have a significant positive impact on the investment performance.

Sattari et al. (2013) showed that the innovative marketing strategies that the business takes in its activities, especially, strategies based on the products, promotional activities and sales promotion, through the entrepreneurial orientation of managers and business decision makers lead to the objective innovations conducted in the products or services offered by the business and to a competitive advantage in terms of differentiation, cost, innovation, growth and establishment of strategic alliances, and the small and medium entrepreneurs using the leverage of the creativity and innovative measures would continue to exist alongside the large companies and by acquiring a sustainable competitive advantage, we seek to challenge their strategies, and achieve the great success globally.

Tayeibi and Fakhri (2010) examined the effects of globalization and international trade on the entrepreneurship development (Case study: OECD countries). In this study, they examined the impacts of international trade and globalization on the development of entrepreneurship. Since the OECD countries enjoy the high level of business relationship and especially play a major role in the development of the World Trade occasions, they have been noted in this study. Discovering answers to questions about the research on the impact of trade and economic globalization on entrepreneurship in developed countries of OECD, this can be a good lesson for the developing countries, especially Iran, to develop entrepreneurship. To achieve this goal, a specified econometric model and using panel data selected from OECD countries over $2000-2005$ were estimated. The results suggest that the development of exports and imports and globalization phenomenon have the significant positive impact on the level of entrepreneurship in the concerned countries and establishing an overflow and technology transfer with foreign trade plays an important role in the entrepreneurship development process.

Shah Abadi et al. (2012) examined the role of innovation and competitiveness on the Islamic countries', D8, export performance. They examined the role of fundamental variables of innovation, competitiveness, R \& D activities and labor productivity on the export of D8 countries during the 1980-2009. The results of this study indicate poor condition of export, innovation and competitiveness of the study countries compared to the developed countries, so these countries should pay more attention to the fundamental variables such as innovation, which are highlighted their contributions on the export performance, today. Therefore, in order to reduce the technology gap, increasing the competitiveness strength and achieving sustainable economic growth and stability, and using macroeconomic policies to focus on the components of economic knowledge and technology transferring agents should be emphasized on export performance.

Safari and Nagorno Bashlou (2014) examined the relationship between entrepreneurial marketing and marketing performance through innovation in a case study: the companies operating in the industrial automation industry, telecommunications, computer and digital equipment. The study investigated the effect of entrepreneurial marketing on the innovation, taking into account the moderating effect of two factors including tendency to learning and organizational structure, and measured the relationship between the innovation and marketing function within the study templates. The statistical population consisted of the marketing and sales employees and managers of 42 companies active in three industrial automation, telecommunications, computer and digital equipment industries. Data collection method is the research-made questionnaires with reliability and validity, which are acceptable that 250 questionnaires were distributed between the managers and employees in marketing and sales departments of 42 companies in three intended industries that 195 were returned and analyzed. The results showed the entrepreneurial marketing has an impact on the innovation, and the innovation, on the marketing performance. Also, the learning orientation and organizational structure have the moderating effect on 
the relationship between the entrepreneurial marketing and the innovation.

\subsection{Design of the Study}

In this study, patterning the model of Kiran et al. (2012), the conceptual model was designed as figure below:

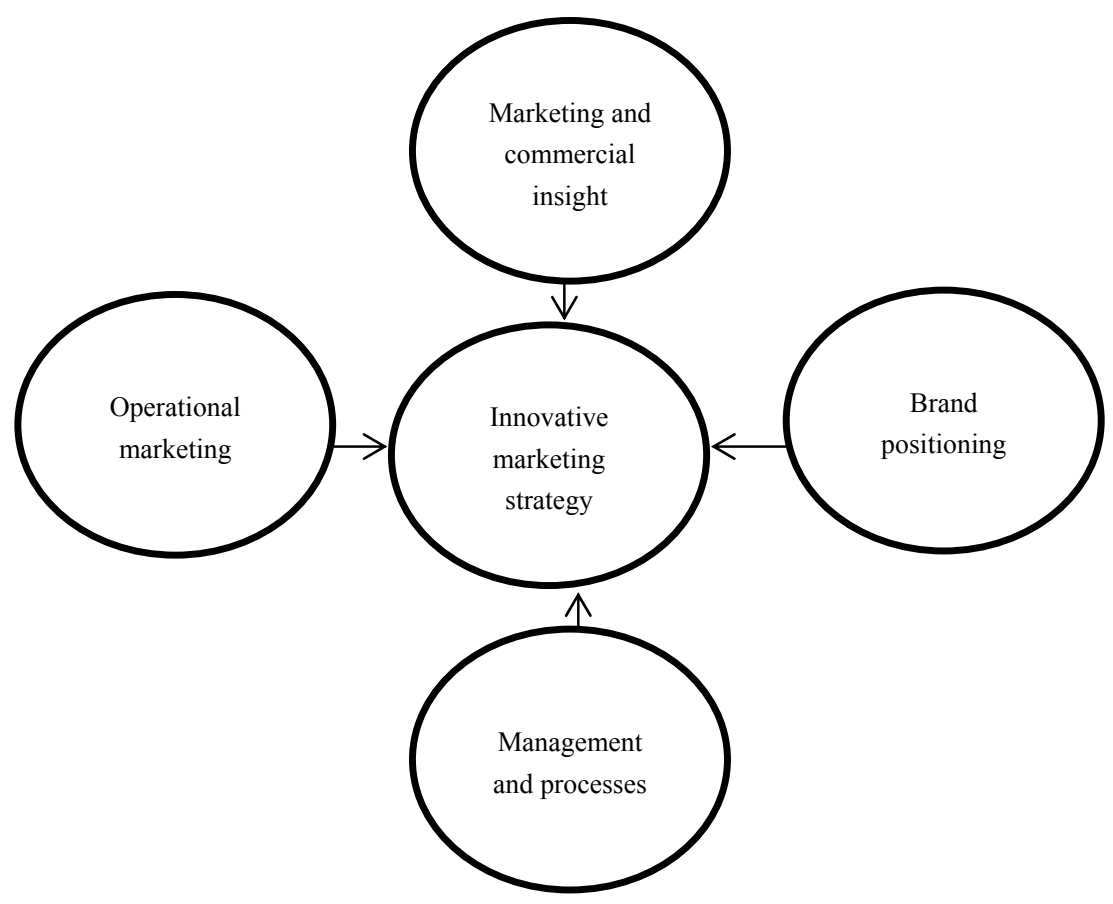

Figure 3. Conceptual model of the study

\section{Research Hypothesis}

In providing innovative marketing model, the following hypotheses were raised: H1: Processes and management are effective in developing innovative marketing strategy.

$\mathrm{H} 2$ : Operational marketing is effective in the innovative marketing strategy.

H3: Marketing and commercial insight are effective in developing innovative marketing strategy.

H4: Brand positioning is effective in the innovative marketing strategy.

This study is a descriptive one, which is applied by survey method. Data were collected by the questionnaire drawn from research Kiran et al. (2012). The questionnaire included 26 items. The statistical population consisted of the members of the Union of Manufacturers and exporters of furniture of Iran, in Tehran that included 10 companies randomly, referred to corporate headquarters of the study companies when conducting the research. Thirty questionnaires were distributed in each company. After a week, 130 questionnaires were collected.

\subsection{Research Variables and Models}

In order to ensure the quality of data collected and understand the general characteristics of the sample, its demographic variables can be expressed. The demographic information of sample statistics is shown in Table 2 and 3 .

Table 2. Demographic information based on gender

\begin{tabular}{ccc}
\hline Gender & Number & Percentage \\
\hline Female & 36 & $28 \%$ \\
Female & 94 & $72 \%$ \\
\hline
\end{tabular}


Table 3. Demographic information based on education

\begin{tabular}{ccc}
\hline Education & Number & Percentage \\
\hline Diploma & 11 & $\% 8$ \\
D.H.E & 38 & $29 \%$ \\
B.S. & 57 & $44 \%$ \\
M.A & 24 & $18 \%$ \\
\hline
\end{tabular}

\subsection{Reliability and Validity of Variables}

Since the standard questionnaire is used to measure the variables, first the indicators were translated and then, referring to the elites the modifications were approved. In Figure 1, as seen, all variables loads have a value greater than 0.5 , indicating that the reliability of the measurement model is acceptable. Then, the reliability of variables by Cronbach's alpha indicated a high standard rate of 0.7 (Cronbach, 1951) and the composite reliability (CR) greater than 0.7 and average variance expended (AVE) with the standard rate greater than 0.5 (Fornell \& Lacker, 1981) were evaluated by Smart-PLS software. Table 4 indicates the reliability.

Table 4. Reliability of the variables

\begin{tabular}{ccccc}
\hline Variable & Number of questions & Cronbach alpha & AVE & CR \\
\hline Brand positioning & 4 & 0.862179 & 0.708357 & 0.906221 \\
Innovative marketing & 6 & 0.835119 & 0.552024 & 0.879702 \\
Commercial approach & 4 & 0.765006 & 0.583758 & 0.847294 \\
Operational marketing & 4 & 0.873954 & 0.727173 & 0.913669 \\
Processes & 4 & 0.864728 & 0.713987 & 0.908127 \\
\hline
\end{tabular}

\subsection{Divergent Validity (Fornell and Lark's Method)}

In the divergent validity, the difference between the indicators of a structural model has been compared with other structures ones. It is calculated by comparing the square root of AVE for each structure with the correlation coefficient values between structures. To do so, a matrix is formed the main diagonal values are the square root of AVE coefficients for each structure and the lower and higher values of main diagonal are the correlation coefficients between each structure and other structures. The matrix is shown in Table 5 .

Table 5. Matrix square root of AVE and correlation coefficients of structures

\begin{tabular}{lccccc}
\hline & $\begin{array}{c}\text { Brand } \\
\text { positioning }\end{array}$ & $\begin{array}{c}\text { Innovative } \\
\text { marketing }\end{array}$ & $\begin{array}{c}\text { Commercial } \\
\text { approach }\end{array}$ & $\begin{array}{c}\text { Operational } \\
\text { marketing }\end{array}$ & Processes \\
\hline Brand positioning & 0.8416395 & & & & \\
Brand positioning & 0.699095 & 0.7429832 & & & \\
Brand positioning & 0.451722 & 0.320558 & 0.7640406 & & \\
Brand positioning & 0.523437 & 0.651425 & 0.260937 & 0.8527444 & \\
Brand positioning & 0.411029 & 0.643308 & 0.078601 & 0.440542 & 0.8449775 \\
Brand positioning & 0.8416395 & & & & \\
\hline
\end{tabular}

According to the matrix above, the square root of AVE for each structure is greater than the correlation coefficient between this structure and other structures, indicating the acceptability of the Divergent validity of the structures.

\section{Data Analysis and Results}

As shown in Figure 4, the coefficient path value has been calculated 0.408 for the relationship between two 
variables, processes and innovative marketing; and according to Figure 2, it can be seen, a significant amount is calculated by 10.61 but not ranged in $(-1.96,1.96)$. It can be concluded that the path coefficient is significant at the error level of 0.05 .In other words, implying that process as a variable has a positive and significant impact on the innovative marketing, the first hypothesis is confirmed.

The path coefficient is calculated 0.541 for the relationship between two variables, operational marketing and the innovative marketing. According to Figure 5, a significant amount of 11.658 obtained for the path is not ranged in $(-1.96,1.96)$. It can be concluded that the path coefficient is significant at the error level of 0.05 .In other words, implying the variable of operational marketing has a significant negative effect on the innovative marketing, the second hypothesis is confirmed.

The path coefficient is calculated 0.044 for the relationship between two variables, commercial approach and innovative marketing, and according to Figure 5, it can be seen a significant amount of 1.925 obtained for this path is not ranged in $(-1.96,1.96)$. It can be concluded that this path factor is not significant at the error level of 0.05 , in other words, implying that the variable of commercial approach does not have a significant effect on the innovative marketing. Thus, the third hypothesis is rejected.

The path coefficient is calculated 0.229 for the relationship between two variables, brand positioning and innovative marketing. According to Figure 5, it can be seen a significant amount of 7.201 obtained for this path is ranged in $(-1.96,1.96)$. It can be concluded that the path coefficient is significant at the error level of 0.05 , implying that the variable of operational marketing has a significant negative effect on the innovative marketing and the fourth hypothesis is confirmed.

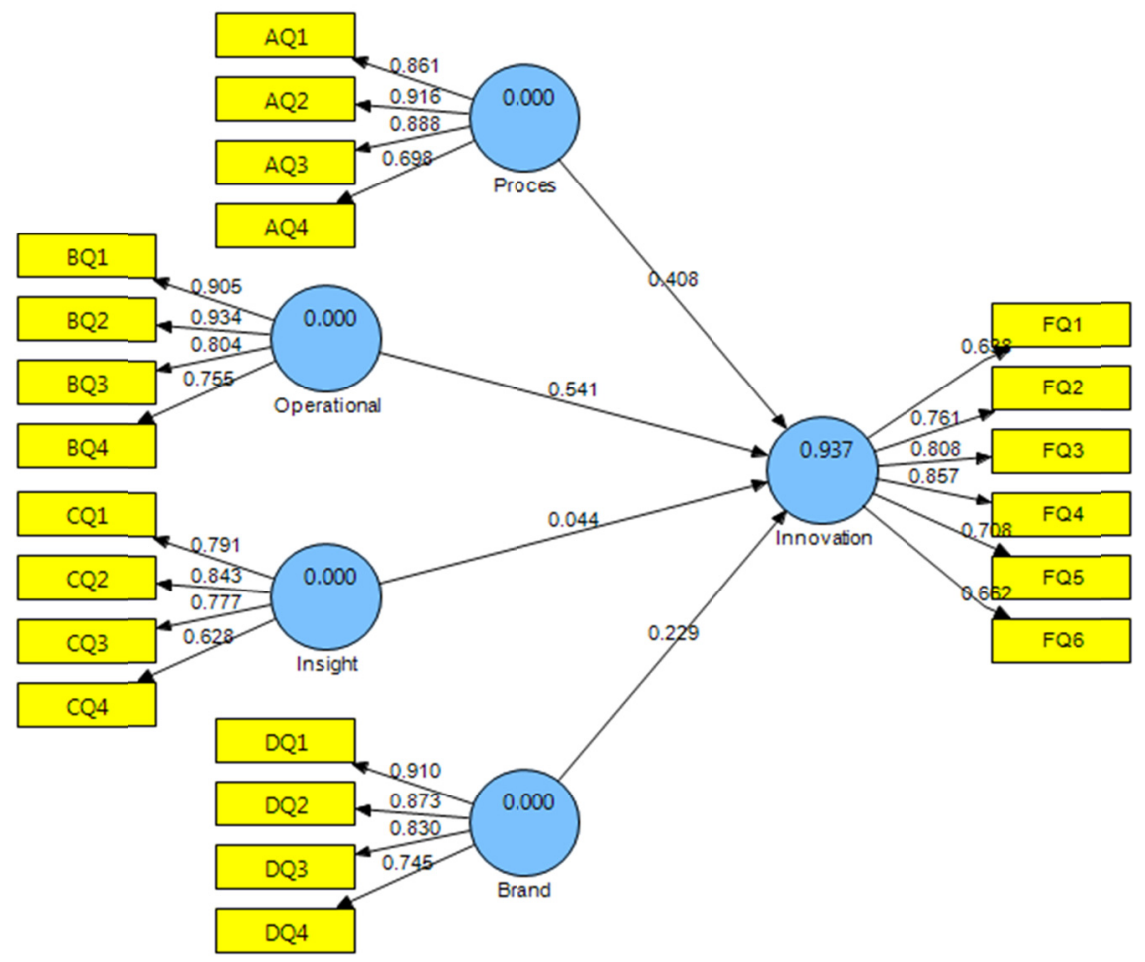

Figure 4. The estimated standard model 


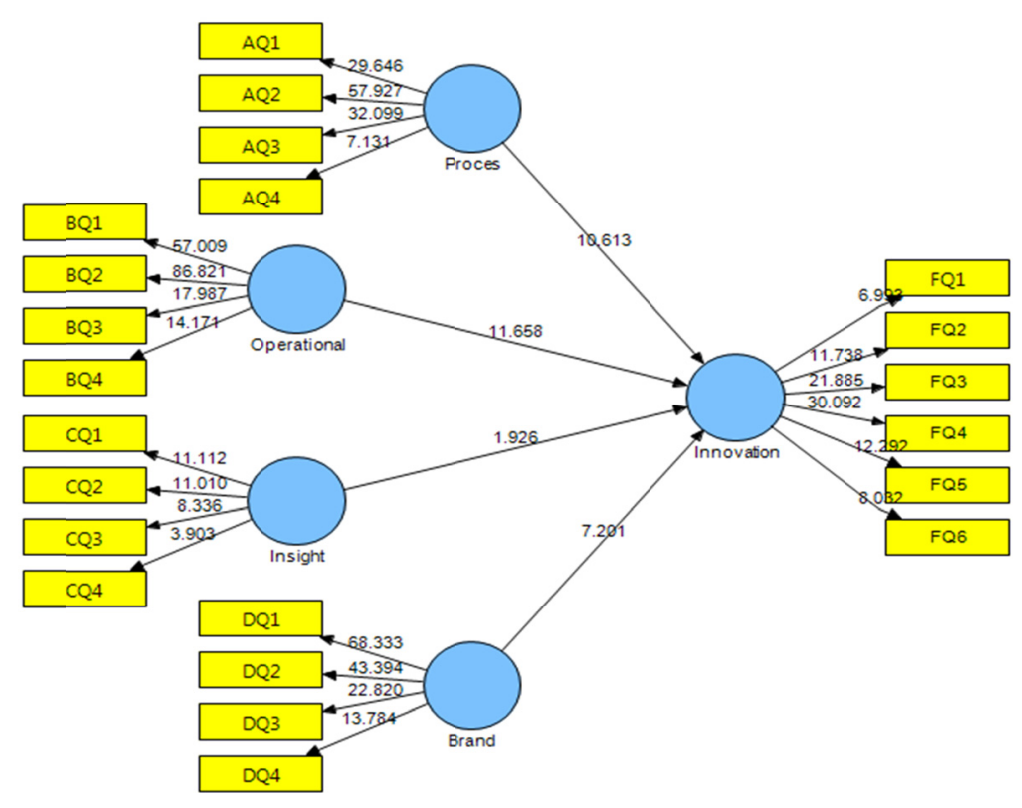

Figure 5. The model of significant parameters $(t)$

\section{Studying Model Parameters}

To check the quality or validity of the model, the credit check is used which includes the share credit indicator and redundant quality check indicator or redundancy. Share index measures the quality of the measurement model of each block. Redundant indicator of $\mathrm{Q}^{2}$ also known as the Stone-Gycerate, the positive values of the indicators indicate the acceptable and good quality of the measurement and structure models.

In Figure 6 and Table 6, the values of each of the indicators related to the dependent and independent variables are presented. As seen, the indicators are positive and greater than zero.

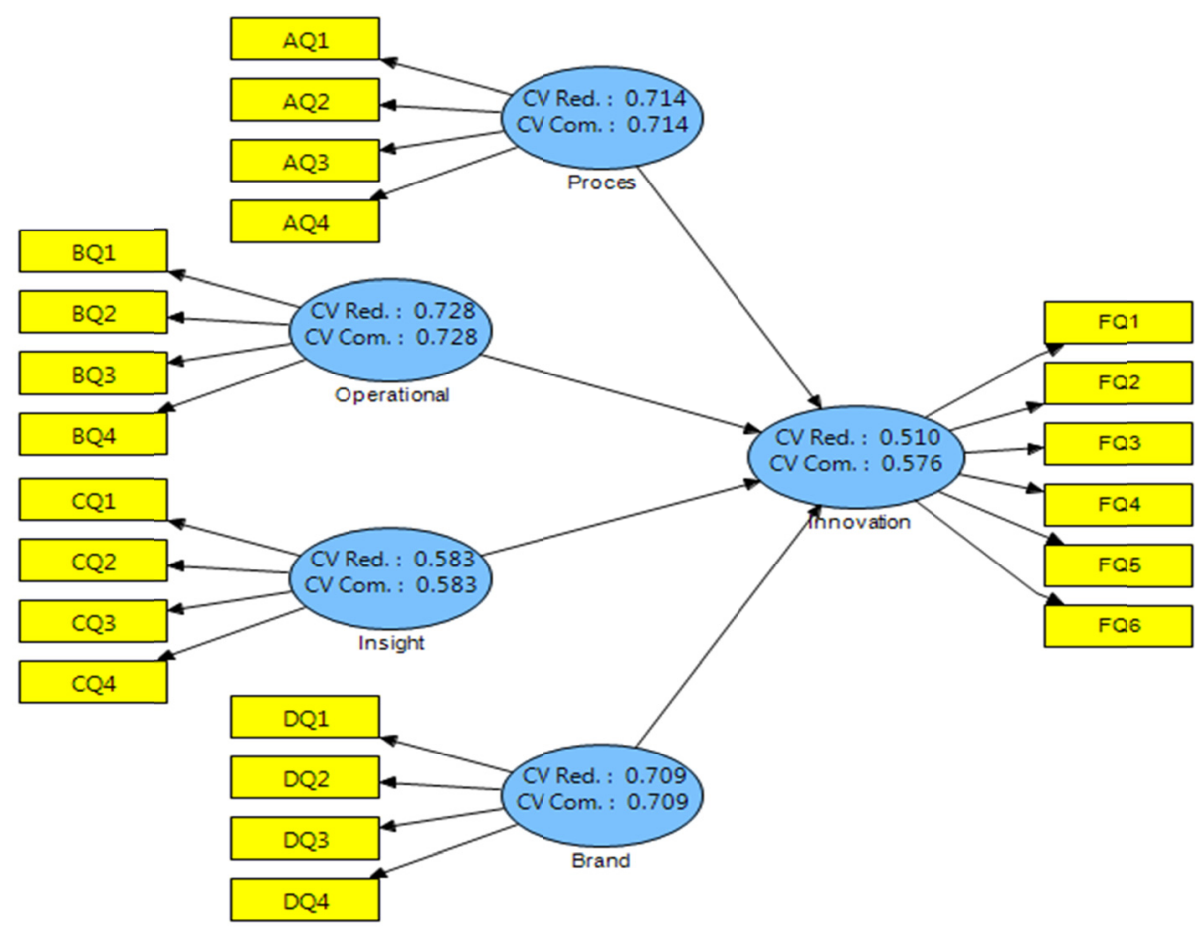

Figure 6. Indicators of model's fit 
Table 6. Share indicators (CV Com) and redundant indicator (CV Red)

\begin{tabular}{ccc}
\hline & CV Red & CV Com \\
\hline Brand positioning & 0.708800 & 0.708800 \\
Innovative marketing & 0.510478 & 0.575975 \\
Commercial approach & 0.582726 & 0.582726 \\
Operational marketing & 0.727651 & 0.727651 \\
Processes & 0.713581 & 0.713581 \\
\hline
\end{tabular}

\section{Conclusion}

The degree of compliance and standardization of marketing programs is very important in international trade. Since international activities are vital for the functioning of export companies, the companies face the challenge of designing and implementing export strategies specified for the market, within the target markets are rapidly changing as an uncertain environment. This article provides a model for the innovative marketing strategies in international entrepreneurship. The analysis of the data shows the business approach has a significant effect on the innovative marketing. This indicates that, to apply the innovative marketing and the innovative marketing strategy development, the managers do not have enough knowledge to use information, and the results of this study could be considered consistent with the results of the research by Marius et al, implying that the managers would not have enough knowledge to use the innovative marketing information. Other hypotheses 'results are consistent with the Kiran et al. (2012). The innovative marketing is not only related to developing new products, services and technologies, but also is one of the main factors that companies can better meet the needs of customers, using it correctly, compared with the competitors in the intensively-competitive environment and they survive in this way.

\section{References}

Aditya, A., \& Acharya, R. (2013). Export diversification, composition, and economic growth: Evidence from cross-country analysis. J. Int. Trade Econ. Dev., 22(7), 959-992. http://dx.doi.org/10.1080/09638199.2011. 619009

Alex, M., de Waal, A., \& Verhoeven, B. (2011). Entrepreneurial and innovative marketing: A systematic review of the literature. Innovative Marketing, 7(4).

Briggs, M. (2011). Pegasus Town: Innovative marketing of a new property venture. Marketing Intelligence \& Planning, 29(6), 602-610. http://dx.doi.org/10.1108/02634501111166111

Calof, J. L., \& Beamish, P. W. (1995). Adapting to foreign markets: Explaining 7 Internationalization. International Business Review, 4(2), 115-131. http://dx.doi.org/10.1016/0969-5931(95)00001-G

Carlos, Q., \& Tan Sousa, M. P. (2015). Leveraging marketing capabilities into competitive advantage and export performance. International Marketing Review, 32(1), 78-102. http://dx.doi.org/10.1108/IMR-12-2013-0279

Carson, D., Gilmore, A., Cummins, D., O’Donnell, A., \& Grant, K. (1998). Price 9. Setting in SMEs: Some empirical findings. Journal of Product \& Brand Management, 7(1), 74-86. http://dx.doi.org/10.1108/106 10429810209755

Chetty, S. K., \& Stangl, L. M. (2010). Internationalization and innovation in a network relationship context. European Journal of Marketing, 44(11/12), 1725-1743. http://dx.doi.org/10.1108/03090561011079855

Chung, H. F. L. (2007).International marketing standardization strategies analysis: across-national investigation. Asia Pacific Journal of Marketing and Logistics, 19(2), 145-167. http://dx.doi.org/10.1108/135558507107 38499

Damanpour, F., Walker, R. M., \& Avellaneda, C. N. (2009). Combinative effects of innovation types and organizational performance: A longitudinal study of service organizations. Journal of Management Studies, 46(4), 650-675. http://dx.doi.org/10.1111/j.1467-6486.2008.00814.x

Doyle, P. (2008). Value-Based Marketing-Marketing Strategies for Corporate Growth and Shareholder Value (2nd ed.). John Wiley \& Sons, England.

Evangelista, R., \& Vezzani, A. (2010). The economic impact of technological and organizational innovations: A firm-level analysis. Research Policy, 39(10), 1253-1263. http://dx.doi.org/10.1016/j.respol.2010.08.004 
Forsman, H. (2011). Innovation capacity and innovation development in small enterprises. A comparison between the manufacturing and service sectors. Research Policy, 40(5), 739-750. http://dx.doi.org/10.1016/j. respol.2011.02.003

Giannakouris, K., \& Smihily, M. (2010). ICT Usage in Enterprises 2010. Retrieved June 6, 2012, from http://epp.eurostat.ec.europa.eu/cache/ITY_OFFPUB/KS-QA-10-049/EN/KS-QA-10-049-EN.PDF

Hart, J. S. (1994). Export marketing research and the effect of export experience in industrial SME. International Marketing Review, 11(6), 4-22. http://dx.doi.org/10.1108/02651339410072980

Horn, A. S., Hendel, D. D., \& Fry, G. W. (2007). Ranking the international dimension of top research universities in the United States. Journal of Studies in International Education, 11(3/4), 330-58. http://dx.doi.org/10. $1177 / 1028315306294630$

Jullan, B., Hamel, G., \& Michael, J. M. (2008). Management Innovation. Academy of Management Review, 33(4), 825-845. http://dx.doi.org/10.5465/AMR.2008.34421969

Kanagal, N. B. (2015). Innovation and product innovation in marketing strategy. Journal of Management and Marketing Research, 18, February.

Kraus, S., Harms, R. \& Fink, M. (2010). Entrepreneurial marketing: moving beyond marketing in new ventures. International Journal of Entrepreneurship and Innovation Management, 11(1), 19-34. http://dx.doi.org/10. 1504/IJEIM.2010.029766

Li-Hua, R., Wilson, J., Aouad, Gh., \& Li, X. (2011) .Strategic aspects of innovation and internationalization in higher education. Journal of Chinese Entrepreneurship, 3(1), 8-23. http://dx.doi.org/10.1108/175613911111 05990

McDougall, P. P., \& Oviatt, B. M. (2000). International entrepreneurship: The intersection of two research paths. Academy of Management Journal, 43(5), 902-906. http://dx.doi.org/10.2307/1556418

Meshram, K., \& Chavan, S. R. (2011). The role of CRM in Indian SMEs growth: Issues and Challenges. Hi-Tech Research Analysis Journal, 1(2).

Myers, M. B., Cavusgil, S. T., \& Diamantopoulos, A. (2002). Antecedents and actions of export pricing strategy: A conceptual framework and research propositions. European Journal of Marketing, 36(1/2), 159-188. http://dx.doi.org/10.1108/03090560210412746

Okayaki, S., Taylor, C. R., \& Zou, S. (2006).Advertising standardization's positive impact on the bottom line: A model and when and how standardization improves financial and strategic performance. Journal of Advertising, 35(3), 17-33. http://dx.doi.org/10.2753/JOA0091-3367350302

Óscar, R., Vence, X., \& Carmen Sánchez, M. D. (2015). The relationship between innovation and export behavior: The case of Galician firms, Technological Forecasting \& Social Change.

Oviatt, B., \& McDougall, P. (2007). International entrepreneurship and its globalization rate (Trans: M. Zeev Dar). Management, 129, 51-56.

Panah Baygi, S. R., \& Naserkhany, S. (2013). The effect of international entrepreneurship and the use of marketing on the adaptability of the marketing mix elements through mediation role of uncertainty in the marketing strategy. The first national conference on accounting and management position in the modern world of business, economics and culture.

Potgieter, M., de Jager, J. W., \& van Heerden, N. H. (2013). An innovative marketing information system: A management tool for South African tour operators. Procedia-Social and Behavioral Sciences, 99, 733-741. http://dx.doi.org/10.1016/j.sbspro.2013.10.545

Robles, F. (2011). Export channel integration strategy and performance: A contingency approach. International Journal of Business and Management, 6(12), 3-13. http://dx.doi.org/10.5539/ijbm.v6n12p3

Safari, A., \& Gharaneh Bashloni, R. (2014). Evaluating the link between entrepreneurial marketing and marketing performance through innovation (case study: companies operating in the industrial automation industry, telecommunications, computer and digital equipment). Business Management, 6(4), 809-826.

Sattari, B., \& Esmailpour, H. (2015). Review on relationship between the desire to exports, technologic innovation and size of organizations in small and medium industry in the global markets environment. European Online Journal of Natural and Social Sciences, 4(1).

Sattari, B., \& Navazeni, B. (2015). Studying the effect of information technology and social networks on 
international entrepreneurial business (Case study: nontechnology companies). Journal of Current Research in Science (JCRSDJ), 3(4), 45-52.

Sattari, B., \& Navazeni, B. (2015). The role of international entrepreneurial strategies in the field of tourism on gross domestic production (GDP). Journal of Current Research in Science (JCRSDJ), 3(6), 73-88.

Sattari, B., Haghighinasab, M., Ebrahimi, M., \& Roghanian, P. (2013). The Effect of Channel Function Performance on Relationship Quality with Organizational Buyers: A Case Study in Iranian Food Distribution Company. IJFPSS, 3(3), 42-47. http://dx.doi.org/10.14331/ijfpss.2013.330033

Sattari, B., Haghighinasab, M., Ebrahimi, M., \& Roghanian, P. (2013). Identification of Innovative Marketing Strategies to Increase the Performance of SMEs in Iran. IJFPSS, 3(2), 26-30.

Sousa, C. M. P., Martínez-López, F. J., \& Coelho, F. (2008). The determinants of export performance: A review of the research in the literature between 1998 and 2005.

Stokes, D. (1995). Small business management (2nd ed.). London: DP Publishing.

Taghavi, A. (2011). Providing innovative marketing model in supply chain management under approach of IT: Creating higher value (MSc. Thesis). K.N. Toosi University of Technology, Industrial Engineering Department.

Tayebi, S. K., \& Fakhari, M. (2010). The effects of globalization and international trade on the development of entrepreneurship, case study countries (OECD).

Tomislav, S., Radojevic, P., \& Lekovic, J. (2015). The standardization /adaptation dilemma in agree-food exporters marketing strategies. British Food Journal, 117(11).

Vasanth, K., Majumdar, M., \& Kishore, K. (2012). Innovative marketing strategies for micro, small \& medium enterprises. Institute of Interdisciplinary Business Research, 4(2).

Vrontis, D., Thrassou, A., \& Lamprianou, I. (2009). International marketing adaptation versus standardization of multinational companies. International Marketing Review, 26(4/5), 477-500. http://dx.doi.org/10.1108/026 51330910971995

Wirtz, B. W., Mathieu, A., \& Schilke, O. (2007). Strategy in high-velocity environments. Long Range Planning, 40, 295-313. http://dx.doi.org/10.1016/j.lrp.2007.06.002

\section{Copyrights}

Copyright for this article is retained by the author(s), with first publication rights granted to the journal.

This is an open-access article distributed under the terms and conditions of the Creative Commons Attribution license (http://creativecommons.org/licenses/by/4.0/). 